
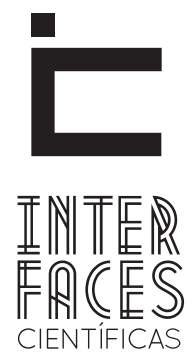

DIREITO

ISSN IMPRESSO 2316-3321

E - ISSN 2316-381X

DOI - 10.17564/2316-381X.2017v6n1p35-52

\title{
VIOLAÇÃO MIDIÁTICA DA PRIVACIDADE E DA HONRA DE ADOLESCENTES ACUSADOS DE ATOS INFRACIONAIS NO ESTADO DE SERGIPE
}

\author{
VIOLATION OF THE PRIVACY AND THE HONOR OF ADOLESCENTS ACCUSED OF UNLAWFUL ACTS IN THE STATE OF SERGIPE \\ VIOLACIÓN MIDIÍTICA DE LA PRIVACIDAD Y DEL HONOR DE ADOLESCENTES ACUSADOS DEHECHOS INFRACCIONALES ENEL ESTADO DE SERGIPE
}

Moacir Silva do Nascimento Júnior

\section{RESUMO}

0 presente trabalho analisa a normatividade nacional e internacional que tutela os direitos humanos dos adolescentes acusados da prática de atos infracionais, a partir dos dispositivos constitucionais, convencionais e legais, levando em conta a posição adotada pela doutrina especializada. A partir desses parâmetros jurídicos e da pesquisa de notícias publicadas no principal veículo de comunicação "online" de cada um dos sete municípios mais populosos do Estado de Sergipe, excluída a Região Metropolitana, constata o elevado grau de violação, sobretudo da honra e da privacidade dos ado- lescentes acusados. Busca, diante dessa problemática, refletir quanto à ineficácia jurídica dos dispositivos protetivos e propor estratégias para uma maior efetividade da política pública de fiscalização e de repressão desse tipo de violação do direito fundamental ao respeito.

\section{PALAVRAS-CHAVE}

Direitos Humanos. Imprensa. Sistema de Justiça. 


\section{ABSTRACT}

The present study analyzes the national and international normativity that protects the human rights of adolescents accused of the practice of infractions, from the constitutional, conventional and legal, taking into account the position adopted by the specialized doctrine. Based on these legal parameters and the search for news published in the main vehicle for online communication of each of the seven most populous municipalities in the State of Sergipe, excluding the Metropolitan Region, the high degree of violation of the honor and privacy of Teenagers accused.
It seeks, in the face of this problem, to reflect on the legal inefficiency of the protective devices and to propose strategies for greater effectiveness of the public policy of inspection and repression of this type of violation of the fundamental right to respect.

\section{KEYWORDS}

Human Rights. Press. System of Justice.

\section{RESUMEN}

El presente trabajo analiza la normatividad nacional e internacional que tutela los derechos humanos de los adolescentes acusados de la práctica de hechos infraccionales, a partir de los dispositivos constitucionales, convencionales y legales, teniendo en cuenta la posición adoptada por la doctrina especializada. A partir de esos parámetros jurídicos y de la investigación de noticias publicadas en el principal vehículo de comunicación en línea de cada uno de los siete municipios más populosos del Estado de Sergipe, excluida la Región Metropolitana, constata el alto grado de violación sobre todo al honor y la privacidad de los adolescentes acusados. En esta problemática reflexiona sobre la ineficacia jurídica de los dispositivos protectores y propone estrategias para una mayor efectividad de la política pública de fiscalización y de represión de ese tipo de violación del derecho fundamental al respeto.

\section{PALABRAS CLAVE}

Derechos Humanos; Prensa; Sistema de Justicia. 


\section{INTRODUÇ̄̃̃O}

A infância e a juventude não passam incólumes pela crescente onda de criminalidade, problema comum a todas as regiões brasileiras. Seja como vítimas de bárbaros crimes, contra a vida, contra a dignidade sexual, dentre outros, seja como autores de ilícitos de igual gravidade, adolescentes são frequentemente protagonistas de matérias jornalísticas publicadas por diversos veículos de comunicação, sobretudo com o advento das mídias virtuais, que viabilizam a qualquer pessoa, com investimentos mínimos, propagar notícias com aparência de profissionalismo.

Este trabalho analisa a realidade sergipana, a partir de pesquisa realizada por meio da Internet em veículos de comunicação dos municípios de Nossa Senhora da Glória, Simão Dias, Itabaianinha, Tobias Barreto, Estância, Itabaiana e Lagarto, os sete mais populosos, excluída a região metropolitana, principais responsáveis pela disseminação de informações de interesse público, referentes a fatos com repercussão local ou regional, já que a população não conta com a cobertura mais intensa de emissoras televisivas, sediadas na Capital e a mídia impressa está perdendo cada vez mais espaço para as virtuais.

0 trabalho também reflete sobre o fenômeno midiático de exploração da violência, que faz parte da estratégia de comunicação social adotada pelos próprios órgãos públicos integrantes do sistema de segurança pública e defesa social, aborda a situação específica, do ponto de vista jurídico, dos adolescentes acusados da prática de atos infracionais, com enfoque na doutrina da proteção integral e nos direitos fundamentais tutelados por normas constitucionais, convencionais e legais.

Ao final do trabalho, são expostos os resultados do levantamento realizado nos veículos de comunicação antes mencionados, explicitando os parâmetros normativos utilizados para verificação do grau de violação dos direitos humanos dos adolescentes acusados, sugerindo estratégias de enfrentamento a serem adotadas pelos órgãos públicos integrantes do Sistema de Garantia dos Direitos da Criança e do Adolescente, especialmente o Ministério Público, o Poder Judiciário e por entidades ligadas aos movimentos sociais.

\section{DIREITO FUNDAMENTAL AO RESPEITO DOS ADOLESCENTES ACUSADOS DE ATOS INFRACIONAIS}

A Constituição Federal consagrou, por meio de diversos dispositivos, especialmente em seu art. 227, caput ${ }^{1}$, a chamada doutrina da proteção integral, elaborada a partir de debates travados no âmbito da Organização das Nações Unidas, notadamente a partir da década de oitenta (AMIN, 2013), com o intuito de modernizar as diretrizes normativas que incidiam sobre crianças e adolescentes ${ }^{2}$, até então tratados pelos diversos ordenamentos jurídicos como meros objetos a serem tutelados pelo direito, gerando uma atuação estatal que não considerava o seu peculiar estado de pessoa humana em desenvolvimento.

Exemplo dessa linha normativa anteriormente em voga, a Lei n 6.697, de 10 de outubro de 1979, que instituiu o Código de Menores, centrava sua atenção sobre a denominada "situação irregular", atuando quando presentes circunstâncias de fato ligadas à carência e a delinquência, sem prever deveres jurídicos direcionados à promoção de direitos, como políticas públicas na área de educação e de saúde.

1. Art. 227. É dever da família, da sociedade e do Estado assegurar à criança, ao adolescente e ao jovem, com absoluta prioridade, o direito à vida, à saúde, à alimentação, à educação, ao lazer, à profissionalização, à cultura, à dignidade, ao respeito, à liberdade e à convivência familiar e comunitária, além de colocá-los a salvo de toda forma de negligência, discriminação, exploração, violência, crueldade e opressão.

2. Após citar a aprovação das Regras Mínimas das Nações Unidas para a Administração da Justiça da Infância e da Juventude - Regras Mínimas de Beijing, por meio da Resolução $n^{\circ}$ 40/33 da Assembleia-Geral das Nações Unidas, de 29 de novembro de 1985, Andréa Rodrigues Amin (2013, p. 44) afirma que "a nova ordem rompeu, assim, com o já consolidado modelo da situação irregular e adotou a doutrina da proteção integral”. 
João Batista Costa Saraiva (2016, p. 64) sustenta que as novas diretrizes normativas que entraram em vigor com a Constituição Federal e o Estatuto da Criança e do Adolescente, revogaram "a antiga concepção tutelar, trazendo a criança e o adolescente para uma condição de sujeito de direito, de protagonista de sua própria história, titular de direitos e obrigações próprios de sua peculiar condição de pessoa em desenvolvimento". Para ele, tais diretrizes atribuíram “um novo contorno ao funcionamento da Justiça da Infância e Juventude, abandonando o conceito de menor, como sub-categoria de cidadania" (SARAIVA, 2016, p. 64).

Por meio da grande influência exercida pelas discussões posteriores à Segunda Guerra Mundial, amparadas no princípio da dignidade da pessoa humana, a comunidade internacional estabeleceu consensos quanto à necessidade de tratar crianças e adolescentes como sujeitos de direitos, garantindo tanto a defesa quanto a promoção dos seus direitos humanos por meio da atuação conjugada da família, da sociedade e do Estado, ficando a cargo deste equipar instituições e estruturar serviços com o grau de eficiência necessário à correção de históricos quadros de injustiça social e de omissão do poder público.

Como um dos eixos de ação estatal direcionados a crianças e a adolescentes, figura o sistema socioeducativo, para o qual são direcionados os adolescentes acusados de ilícitos previstos na legislação penal, considerando a regra ${ }^{3}$ de inimputabilidade daqueles que não atingiram a idade adulta, por adoção do critério biológico no plano constitucional. Para as crianças, pessoas que não atingiram a idade de 12 (doze) anos completos, a legislação brasileira restringe a atuação estatal às medidas de proteção previstas no Estatuto da Criança e do Adolescente, ante a vedação expressa de aplicação de qualquer medida socioeducativa.

Por mais grave que seja o ato ilícito, como homicídio, latrocínio, tráfico de drogas, não se permite ${ }^{4}$ 3. Art. 228. São penalmente inimputáveis os menores de dezoito anos, sujeitos às normas da legislação especial.

4. 0 art. 105 do Estatuto da Criança e do adolescente prescreve que "Ao ato infracional praticado por criança corresponderão as medidas previstas no art. 101". Regulamentando tal disposição, o Conselho Nacional dos Direitos da Criança e do Adolescente (CONANDA) editou a Resolução $n^{\circ} 113$ de 19 de abril de 2006, dispondo nos seguintes termos: "Art. 12 Somente sequer a instauração de procedimento no âmbito policial, cabendo ao Conselho Tutelar atuar com o intuito de aplicar as medidas de proteção que sejam mais adequadas para o caso.

Vê-se, portanto, que a opção do direito brasileiro, quanto ao tratamento de crianças e adolescentes a que se atribua a prática de atos infracionais, é marcada por uma tônica protetiva e não repressiva. Ao fixar que tais pessoas em desenvolvimento, até quando acusadas de atos que causam repulsa social, precisam de atuação estatal voltada prioritariamente ao aspecto promocional de seus direitos humanos, ao invés da simples retribuição por meio de sanções de discutível efetividade, a legislação equaciona a circunstância de que tais episódios de violência representem, na maioria dos casos, apenas um capítulo do longo histórico de falência generalizada das políticas sociais que deram causa ao envolvimento precoce da criança ou do adolescente com o mundo do crime.

Em outras palavras, ao Estado que deixa de prover serviços públicos com um mínimo de qualidade nas áreas de educação e de saúde, para ficar nas duas áreas de maior relevância, não cabe enfrentar o problema da criminalidade, envolvendo crianças e adolescentes com postura unicamente punitiva, posto que em muitos casos o ingresso no sistema socioeducativo representa a primeira abordagem estatal do adolescente que se encontra em situação de risco desde o início de sua existência.

Detectada a prática de ato infracional, cumpre enfrentar a problemática a ela inerente com base em preceitos da doutrina da proteção integral, reconhecendo que aquele acusado precisa, antes de punição, do aporte de serviços com o mais alto grau de qualificação, respeitando sempre os direitos fundamentais assegurados pela Constituição Federal a todos os acusados e aqueles aplicáveis a crianças e a adolescentes.

A Convenção sobre os Direitos das Crianças da Organização das Nações Unidas, que vigora no Brasil por força do Decreto $n^{\circ} 99.710$, de 21 de novembro

os conselhos tutelares têm competência para apurar os atos infracionais praticados por crianças, aplicando-lhes medidas especificas de proteção, previstas em lei, a serem cumpridas mediante requisições do conselho (artigo 98, 101,105 e 136, III, “b” da Lei 8.069/1990)". 
de 1990, com status supralegal ${ }^{5}$, dispõe sobre o dever de tratamento de crianças - entendida pelo art. $1^{\circ} \mathrm{da}$ Convenção como todo ser humano com menos de dezoito anos de idade - acusadas de atos infracionais, "levando em consideração a idade" e a "importância de se estimular sua reintegração e seu desempenho construtivo na sociedade" (Artigo 40,1).

Esta Convenção dispõe sobre as garantias mínimas aplicáveis a todas as crianças acusadas de infringir leis penais, dentre as quais se destaca o respeito à sua condição de inocente enquanto não comprovada a culpa, o julgamento célere por órgão judicial, a faculdade de arrolar testemunhas de defesa e "ter plenamente respeitada sua vida privada durante todas as fases do processo" (Artigo 40, 2, b, VII).

O Pacto de São José da Costa Rica, convenção de direitos humanos aprovada pela Organização dos Estados Americanos, que também goza de status supralegal, tendo sido promulgado pelo Decreto $\mathrm{n}^{\circ} 678$, de 6 de novembro de 1992, dispõe sobre o direito humano à proteção da honra e da dignidade, nos seguintes termos: "Ninguém pode ser objeto de ingerências arbitrárias ou abusivas em sua vida privada, na de sua família, em seu domicílio ou em sua correspondência, nem de ofensas ilegais à sua honra ou reputação" (Artigo 11, 1).

No mesmo dispositivo, prevê o direito à "proteção da lei contra tais ingerências ou tais ofensas" (Artigo 11, 3), para mais adiante prescrever, como regra de efetividade da proteção da honra e da reputação, que "toda publicação ou empresa jornalística, cinematográfica, de rádio ou televisão, deve ter uma pessoa responsável que não seja protegida por imunidades nem goze de foro especial" (Artigo 14, 3, destaque acrescido).

A Lei $n^{0} 12.965$, de 23 de abril de 2014, ao estabelecer os princípios, as garantias, os direitos e os deveres para o uso da Internet no Brasil, consagra como fundamentos tanto "o respeito à liberdade de expressão", quanto "os direitos humanos, o desenvolvimento da personalidade e o exercício da cidadania em meios digitais" (art. $2^{\circ}$, caput e inciso II) e elenca,

5. Entendimento firmado pelo Supremo Tribunal Federal no julgamento do Recurso Extraordinário $n^{\circ}$ 466.343, em 3/12/2008, que deu origem à edição da Súmula Vinculante n 25 , assim redigida: “É ilícita a prisão civil de depositário infiel, qualquer que seja a modalidade de depósito". dentre outros, os seguintes princípios: "garantia da liberdade de expressão, comunicação e manifestação de pensamento, nos termos da Constituição Federal; [...] proteção da privacidade; [...] responsabilização dos agentes de acordo com suas atividades, nos termos da lei" (art. $3^{\circ}$, incisos I, II e III).

A entrada em vigor da Constituição Federal marcou a separação, ao menos do ponto de vista jurídico, do autoritarismo que cerceava direitos civis básicos por meio de um regime político ilegítimo e que dependia de práticas antidemocráticas para permanecer no poder. Dentre essas práticas, figurava a censura e a repressão institucionalizada e violenta a iniciativas da sociedade direcionadas a contestar e a apontar incoerências e falhas governamentais, tão importantes ao necessário e contínuo aprimoramento da Administração Pública.

Em razão de um natural movimento pendular que marca a história da humanidade, o texto constitucional foi marcado por dispositivos quase panfletários de uma suposta ruptura institucional, gerando na área jurídica o direcionamento de linhas interpretativas sempre para caminhos mais libertários e menos regulatórios. Assim, a conformação político-jurídica do momento deveria passar à margem de qualquer menção a censura e estabelecer, com muito rigor, garantias constitucionais, dentre as quais a liberdade de informação.

Dirley da Cunha Júnior (2009, p. 672), comentando o direito à crítica jornalística, incluída nessa garantia, sustenta que tal direito "representa uma nota essencial de uma sociedade democrática e madura", explicitando que ele prevalece mesmo sobre direitos individuais da personalidade "quando verdadeira a informação e inevitável a sua transmissão".

Emblemático, nessa linha, o art. 220, $\S 2^{\circ}$, do texto constitucional, ao vedar expressamente, como se isso fosse necessário, "toda e qualquer censura de natureza política, ideológica e artística”. Dentro do clima político que marcou a Constituinte, possível concluir que tal dispositivo deriva de uma pretensão frustrada, no sentido de que, ao restringir de forma absoluta a atuação do Estado em área tão sensível, o mercado 
jornalístico seria dominado por veículos de comunicação isentos, possuidores de linhas editoriais sérias, sem compromissos com grupos políticos ou empresariais que continuam e tendem a continuar, por muito tempo, ditando os rumos da nação com sua influência, sobretudo econômica.

Já que o Direito não se interpreta em tiras, como costumava advertir o Ministro Eros Graú6, é possível afirmar que, mesmo na hipótese de informação jornalística, é possível atribuir sanção jurídica em razão do exercício abusivo da liberdade de informação, mesmo que ela tenha sido conferida pela Constituição Federal nos seguintes termos: "Nenhuma lei conterá dispositivo que possa constituir embaraço à plena liberdade de informação jornalística em qualquer veículo de comunicação social” (art. 220, § 1º). Dentro do poder geral de cautela, cabível inclusive a restrição judicial à circulação da notícia, seja qual for o suporte.

O que a Lei Maior prevê, portanto, é uma cláusula de reserva jurisdicional nessa matéria, ante a garantia da inafastabilidade do controle ${ }^{7}$, que viabiliza a adoção de posturas estatais sancionatórias ou mesmo inibitórias, conforme percepção do magistrado responsável pelo julgamento da causa ${ }^{8}$. Ou seja, ao Poder Executi-

6. Por todas as passagens, cita-se o seguinte trecho de uma das suas decisões monocráticas: "Como afirmei por diversas vezes, o direito não se interpreta em tiras, aos pedaços, de modo que o texto normativo invocado deve ser interpretado em conjunto com os demais preceitos constitucionais relativos à administração da justiça, notadamente os arts. 133 e o princípio assegurado pelo art. $5^{\circ}$, LXXIV”. (Pet 3089 AgR, Relator(a): Min. EROS GRAU, julgado em 15/12/2004, publicado em DJ 01/02/2005 PP-00079, destacado)

7. Art. $5^{\circ}$ [...] XXXV - a lei não excluirá da apreciação do Poder Judiciário lesão ou ameaça a direito;

8. Consta do voto proferido pelo Min. Ricardo Lewandowski no julgamento da ADI 4815, quando o Supremo Tribunal Federal fixou a desnecessidade de autorização de pessoa biografada, de pessoas retratadas como coadjuvantes ou de seus familiares - em caso de pessoas falecidas ou ausentes -, elucidativa passagem referente à possibilidade de restrição anterior à circulação: "eu fiquei muito confortado quando esta Corte, por meio de todos os votos, reafirma que, nesta matéria também, continua prevalecendo, continua válido um princípio absolutamente fundamental, que é aquele da inafastabilidade da jurisdição a que se refere 0 art. $5^{\circ}$, inciso XXXV, da nossa Constituição Federal. Eu entendo, com todo o respeito, que, neste princípio, compreende-se, sim, o poder de cautela do juiz, sobretudo porque esse dispositivo faz menção à ameaça a lesão de direitos, portanto, o juiz deve ter instrumentos para impedir a mera ameaça a lesão de direitos. É claro que - e isso o Ministro decano, Celso de Mello, observou muito bem -, neste conceito, não se compreende qualquer decisão teratológica, até porque existem instrumentos processuais hábeis para fazer cessar de plano, de pronto, qualquer decisão que fuja a esse padrão normal que é o poder geral vo, como antes ocorria, foi vedado o exercício de poder de polícia quando está em jogo a liberdade de informação jornalística. Mas, ao Poder Judiciário, continua conferido o poder/dever de agir quando provocado.

Vidal Serrano Nunes Júnior (2011), analisando o direito à crítica jornalística, explicita que tal direito "se vê limitado pelos direitos à honra, à vida privada e à intimidade", ressalvando que "situações concretas podem ensejar uma colisão do direito de crítica com outros direitos constitucionais, caso em que estes, e não um genérico conceito de ordem público, é que servirão de limite ao direito de crítica”. Em seguida, cita exemplo desse tipo de situação, como a proteção da infância e da juventude prevista no art. 221 da Constituição Federal", que pode "servir de anteparo à crítica jornalística”, e o direito à segurança, "conscrito no caput do art. $5^{\circ}$, pode vir a coibir crítica que, desbordando-se da análise valorativa de fatos, venha a incidir em incitação à prática de crimes" (NUNES JÚNIOR, 2011, p. 136).

É possível concluir, portanto, que a censura, entendida como atividade de órgãos ligados à estrutura administrativa do Poder Executivo, direcionada a controlar e a restringir o direito de crítica exercido por veículos de comunicação e o teor de manifestações políticas, culturais e artísticas, foi expressamente vedada pelo constituinte originário.

Mas a Constituição Federal, ao mesmo tempo em que veda o exercício de atividade censora pelo Poder Executivo, conforme antes exposto, determina, por meio do seu art. 227, caput, que a família, a sociedade e o Estado devem assegurar às crianças e aos adolescentes, neles incluídos aqueles que são acusados da prática de atos infracionais, "com absoluta prioridade, o direito à vida, à saúde, à alimentação, à educação, ao lazer, à profissionalização, à cultura,

de cautela do juiz" (ADI 4815, Relator(a): Min. CÁRMEN LÚCIA, Tribunal Pleno, julgado em 10/06/2015, PROCESSO ELETRÔNICO DJe-018 DIVULG 29-01-2016 PUBLIC 01-02-2016, destacado).

9. Art. 221. A produção e a programação das emissoras de rádio e televisão atenderão aos seguintes princípios: I - preferência a finalidades educativas, artísticas, culturais e informativas; II - promoção da cultura nacional e regional e estímulo à produção independente que objetive sua divulgação; III - regionalização da produção cultural, artística e jornalística, conforme percentuais estabelecidos em lei; IV - respeito aos valores éticos e sociais da pessoa e da família. 
à dignidade, ao respeito, à liberdade e à convivência familiar e comunitária". 0 dispositivo também impõe que tais pessoas, em razão do seu peculiar estágio de desenvolvimento, devem ser colocadas "a salvo de toda forma de negligência, discriminação, exploração, violência, crueldade e opressão".

O Estatuto da Criança e do Adolescente, dando concretude a tais disposições constitucionais, em consonância com os direitos humanos previstos na Convenção dos Direitos da Criança e no Pacto de São José da Costa Rica, vedou, por meio de seu art. 143, caput, "a divulgação de atos judiciais, policiais e administrativos que digam respeito a crianças e adolescentes a que se atribua autoria de ato infracional". A norma, de grande amplitude, consagra garantia contra a violação da honra e da privacidade de crianças e adolescentes acusados de atos infracionais, dando densidade normativa ao direito fundamental ao respeito ${ }^{10}$, que consiste, conforme dicção do art. 17 do Estatuto, "na inviolabilidade da integridade física, psíquica e moral da criança e do adolescente, abrangendo a preservação da imagem, da identidade, da autonomia, dos valores, idéias e crenças, dos espaços e objetos pessoais".

O parágrafo único do art. 147 do Estatuto previu, reconhecendo a importância da liberdade comunicação para o regime democrático, desde a sua redação originária, a possibilidade de veiculação de notícia, envolvendo o fato, desde que ela não identifique a criança ou o adolescente, com vedação expressa do uso de fotografia e da referência a nome, apelido, filiação, parentesco e residência. Por meio da Lei n 10.764 , de 12 de novembro de 2003, foi acrescidaa ${ }^{11}$ a expressão "e, inclusive, iniciais do nome e sobrenome".

10. Leciona Flávio Frasseto (2005, p. 67), que "o direito ao respeito envolve a questão da preservação da imagem, tão freqüentemente violada quando se trata de adolescente infrator. Aqui, tanto quanto o da polícia, é importante o papel da imprensa, em respeitar e, portanto, garantir o direito; o da polícia, em garantir e fazer respeitar, isto é, em promover o direito". Nessa linha, 0 art. 18 do Estatuto enuncia ser "dever de todos velar pela dignidade da criança e do adolescente, pondo-os a salvo de qualquer tratamento desumano, violento, aterrorizante, vexatório ou constrangedor."

11. 0 dispositivo em vigor contém a seguinte redação: “Art. 147 [...] Parágrafo único. Qualquer notícia a respeito do fato não poderá identificar a criança ou adolescente, vedando-se fotografia, referência a nome, apelido, filiação, parentesco, residência e, inclusive, iniciais do nome e sobrenome" (destaque acrescido).
Válter Ishida (2016, p. 412) enfatiza que tal norma tem por objetivo proteger a dignidade e a intimidade dos adolescentes "contra publicações de jornais, revistas, televisão, rádio etc" que realizam a exploração, de forma sensacionalista, da "desgraça alheia e da criminalidade que fornecem alta vendagem e público", razão pela qual a lei coíbe tais abusos também com punições fundamentadas no direito administrativo sancionador; quanto "à liberdade de veiculação de imagens pela imprensa de menores, existe limitação da mesma em prol da dignidade da criança e do adolescente".

Possível concluir, portanto, que um homicídio praticado por adolescente, levando à sua apreensão em flagrante ou não, pode ser objeto de notícia veiculada pela imprensa, desde que não constem da publicação - (a) fotografia; (b) nome; (c) apelido; (d) filiação; (e) parentesco; (f) residência; (g) iniciais do nome e sobrenome. Conforme publicação técnica, voltada a jornalistas, tais vedações buscam preservar os adolescentes acusados de "constrangimentos (que, especialmente no caso de garotos e garotas em conflito com a lei, podem evoluir para retaliações), além de evitar que sua eventual condição de autor de ato infracional seja fixada indeterminadamente no imaginário popular" (BRASIL, 2012, p. 79), o que contraria a peculiar condição de pessoa em desenvolvimento, que demandará, a partir dos fatos apurados, complexo processo de ressocialização.

A curiosidade que naturalmente surge quando graves ilícitos são praticados não pode levar à exposição do adolescente acusado, sob pena de violação do direito fundamental ao respeito. 0 direito de a sociedade obter informações sobre o fato, de grande importância para a democracia, encontra limitadores expressos, previstos nas regras antes citadas, representando conformação político-jurídica, devidamente amparada nos direitos antes referidos.

Como instrumento para inibição da violação dos deveres de proteção ao direito fundamental ao respeito, o Estatuto prevê, em seu art. 247, infração administrativa apenada com multa de até 20 (vinte) salários de referência, passível de majoração até o dobro, em caso de reincidência, para todo aquele que 
“Divulgar, total ou parcialmente, sem autorização devida, por qualquer meio de comunicação, nome, ato ou documento de procedimento policial, administrativo ou judicial relativo a criança ou adolescente a que se atribua ato infracional"12.

A amplitude do tipo sancionador é maior que a do art. 143 do Estatuto, na medida em que o seu $\S 1^{\circ}$ refere a exibição de fotografia, total ou parcial e inclui na vedação a cobertura dos procedimentos que tramitam nas esferas policial, administrativa e judicial. Busca, com isso, preservar a honra e a dignidade das crianças e dos adolescentes acusados da prática de atos infracionais, lançando mão de ferramentas repressivas à disposição do Sistema de Justiça, no âmbito do qual ocorre a apuração das infrações às normas de proteção por meio do procedimento previsto nos arts. 194 a 197 do Estatuto, iniciado por representação do Ministério Público ou por "auto de infração elaborado por servidor efetivo ou voluntário credenciado” (art. 194).

A sanção de multa, após a conclusão do procedimento judicial, será aplicada por decisão devidamente fundamentada, em clara atuação anômala do Poder Judiciário, desempenhando funções de polícia administrativa. Não cabe, nos restritos limites deste trabalho, analisar criticamente tal modelo legal, mas deve

12. Os parágrafos desse dispositivo estão assim redigidos: "§ $1^{\circ}$ Incorre na mesma pena quem exibe, total ou parcialmente, fotografia de criança ou adolescente envolvido em ato infracional, ou qualquer ilustração que the diga respeito ou se refira a atos que the sejam atribuídos, de forma a permitir sua identificação, direta ou indiretamente. $\S 2^{\circ}$ Se o fato for praticado por órgão de imprensa ou emissora de rádio ou televisão, além da pena prevista neste artigo, a autoridade judiciária poderá determinar a apreensão da publicação ou a stuspensão da programação da emissora até por dois dias, bem como da publieação do periódico até por dois números." 0 trecho riscado foi julgado inconstitucional pelo Supremo Tribunal Federal, acatando pedido formulado pelo então Procurador-Geral da República. Consta da ementa: "A Constituição de 1988 em seu artigo 220 estabeleceu que a liberdade de manifestação do pensamento, de criação, de expressão e de informação, sob qualquer forma, processo ou veículo, não sofrerá qualquer restrição, observado o que nela estiver disposto. 2. Limitações à liberdade de manifestação do pensamento, pelas suas variadas formas. Restrição que há de estar explícita ou implicitamente prevista na própria Constituição. Ação direta de inconstitucionalidade julgada procedente. (ADI 869, Relator(a): Min. ILMAR GALVÃo, Relator(a) p/ Acórdão: Min. MAURícIO CORRÊA, Tribunal Pleno, julgado em 04/08/1999, DJ 04-06-2004 PP-00028 EMENT VOL-02154-01 PP-00021). Fazendo-se uma leitura da decisão "a contrario sensu", é possível concluir que o Supremo Tribunal Federal reconheceu a higidez constitucional da proibição contida no tipo sancionador, restringindo a pronúncia da inconstitucionalidade da pena que viola a liberdade de manifestação do pensamento. ser destacado que ele decorre do arranjo institucional que vigorou no Brasil durante décadas, constante do Código de Menores, que garante aos autuados por infrações administrativas o gozo dos direitos à ampla defesa e ao contraditório.

O Estatuto, portanto, ao mesmo tempo em que dispõe de forma bastante rigorosa quando o assunto é tutela do direito fundamental ao respeito de crianças e adolescentes acusados da prática de atos infracionais $^{13}$, inclusive prevendo sanções de multa e de apreensão das publicações, contempla garantias processuais aos acusados de violar os direitos à honra e à privacidade desses adolescentes. Mas as repercussões jurídicas desse tipo de ilícito não se esgotam na seara administrativa.

Como forma adicional de responsabilização, figura a intervenção jurisdicional para a tutela dos direitos da personalidade de cada criança ou adolescente indevidamente exposta, além da possibilidade de lesão a direitos coletivos na hipótese de reiteradas publicações violadores do dever de proteção.

No art. 201, ao dispor sobre o Ministério Público, o Estatuto prescreve que a Instituição pode "promover o inquérito civil e a ação civil pública para a proteção dos interesses individuais, difusos ou coletivos relativos à infância e à adolescência”, destacando, em seu $\S 1^{\circ}$ que "a legitimação do Ministério Público para as ações cíveis previstas neste artigo não impede a de terceiros, nas mesmas hipóteses, segundo dispuserem a Constituição e esta Lei”.

Uma vez que a doutrina da proteção integral exige a atuação não só da família e do Estado, mas também da sociedade, no sentido de defender os direitos fundamentais de crianças e adolescentes, a postura adotada por veículos de comunicação, no sentido de ignorar reiteradamente os comandos normativos que vedam a exposição midiática de adolescentes acusa-

13. 0 Estatuto da Criança e do Adolescente chega a prever sanções penais a serem aplicadas a delegados, membros do Ministério Público e magistrados que violem direitos fundamentais de crianças e adolescentes acusados da prática de atos infracionais, conforme arts. 230, 231 e 234 , este redigido nos seguintes termos: “Art. 234. Deixar a autoridade competente, sem justa causa, de ordenar a imediata liberação de criança ou adolescente, tão logo tenha conhecimento da ilegalidade da apreensão: Pena - detenção de seis meses a dois anos." 
dos da prática de atos infracionais, enquadra-se em ilícito violador de direitos difusos com potencial de causar danos para toda a sociedade.

Tal situação deve receber a devida atenção por parte do Ministério Público e das organizações da sociedade civil que contemplam, em seus objetos sociais, a defesa dos interesses difusos de crianças e adolescentes, com legitimidade para o ajuizamento de ações civis públicas direcionadas à condenação dos violadores contumazes dos deveres antes mencionados e à remoção das publicações, fazendo uso dos instrumentos jurídicos inibitórios consagrados ${ }^{14}$ na legislação brasileira e na doutrina (MARINONI, 2010).

\section{EXPLORAÇ̃̃O DA VIOLÊNCIA PELOS VEÍCULOS DE COMUNICAÇ̃̃O}

O interesse por violência não é uma novidade, já que as práticas de crueldade com animais e as arenas da antiguidade clássica, com gladiadores que atraíam a atenção de grandes massas no Império Romano, episódios reiteradamente retratados em obras cinematográficas e literárias ao longo dos séculos. Esportes que envolvem artes marciais, conduzem, de forma relativamente comum, a desfechos com atletas ensanguentados, até em estágio de inconsciência ou com graves lesões físicas, atraem cada vez mais adeptos, seus eventos e competições são acompanhados com muito interesse por milhões de pessoas de forma simultânea em todo o planeta.

Os veículos de comunicação, especialmente na era da Internet, caminham na direção desse interesse crescente e pautam seu noticiário com muita ênfase em condutas criminosas, que elevarão a audiência e, consequentemente, a venda de espaços publicitá14. Dispõe o Código de Processo Civil, em vigor por força da Lei n ${ }^{13.105}$, de 16 de março de 2015: “Art. 497. Na ação que tenha por objeto a prestação de fazer ou de não fazer, o juiz, se procedente o pedido, concederá a tutela específica ou determinará providências que assegurem a obtenção de tutela pelo resultado prático equivalente. Parágrafo único. Para a concessão da tutela específica destinada a inibir a prática, a reiteração ou a continuação de um ilícito, ou a sua remoção, é irrelevante a demonstração da ocorrência de dano ou da existência de culpa ou dolo" (destaque acrescido). rios, em razão diretamente proporcional à gravidade das condutas praticas. Nessa linha, Gomes e Gazoto (2016, p. 272) reconhecem que "a mídia não é um mal, em si”, mas critica o seu alto poder de repercussão de notícias, destacando que, "além da questão dos seus interesses financeiros - muito bem destacada por Weber - e de uma possível manipulação por grupos específicos, quase sempre suas informações são produzidas urgente e precariamente".

Ao dar grande espaço a atos criminosos praticados, inclusive por adolescentes, sem investigar as causas desse fenômeno, os veículos de comunicação impulsionam políticas de segurança pública que adotam como fundamentos, segundo Gomes e Gazonto (2016, p. 66), a "desigualdade extrema, a força, a violência, ou seja, a destruição da própria sociedade, que viverá submetida a um estado de exceção permanente (com a suspensão dos direitos fundamentais)". Os autores enfatizam ser "o império dos direitos e da lei" o verdadeiro aferidor da evolução social e que "o objetivo a ser perseguido é, por conseguinte, a operatividade deles, não o incremento do estado de exceção (que não passa de desenvolvimento do sub-desenvolvimento)" (GOMES; GAZONTO, 2016, p. 66).

Sérgio Adorno (2002, p. 49) destaca que as "imagens veiculadas pela imprensa e pela mídia eletrônica, cada vez mais frequentes e cotidianas, pintam cenários dramáticos com cores muito fortes". Tais cenários, na grande maioria das vezes, exibem "jovens, alguns até no limiar entre a infância e a adolescência, audaciosos, violentos, dispostos a tudo e prontos para qualquer tipo de ação, inclusive matar gratuitamente" (ADORNO, 2002, p. 49). Essa forma de retratar os jovens é, segundo ele, fruto da requalificação dos jovens, que se intensificou após a Segunda Guerra Mundial, de sujeitos tutelados para sujeitos autônomos e, portanto, na visão social ${ }^{15}$, também responsáveis por seus atos.

15. Disserta Adorno (2002, p. 50-51): “Nesse contexto, os jovens - particularmente adolescentes - sofrem como que um processo de requalificação. De seres tutelados, ganham autonomia. São capazes, por conta própria e movidos por uma lógica social própria à sua geração, de intervir nos rumos da contemporaneidade. Lado a lado com as imagens positivas associadas ao mercado e ao desempenho profissional - entre as quais, voracidade, rapidez, em consonância com o ritmo frenético das sociedades pós-industriais, inteligência e sagacidade -, emergem igualmente imagens negativas que 
Os próprios órgãos encarregados da execução das políticas públicas de defesa ${ }^{16}$ dos direitos humanos de crianças e adolescentes contribuem para a alimentação desse tipo de estratégia midiática, danosa aos direitos fundamentais dos acusados, já que muitas das imagens veiculadas pelos veículos de comunicação são originárias de equipamentos manipulados pelos próprios integrantes das guarnições policiais que realizam a apreensão dos adolescentes, repassando-as logo em seguida por meio de mensagens eletrônicas remetidas do próprio aparelho de telefone celular.

Isso quando não é o próprio órgão de comunicação social da política que produz e publica a notícia na Internet, provavelmente com o intuito de apresentar para a sociedade resultados do trabalho desenvolvido em políticas de segurança pública de discutível efetividade ${ }^{17}$, divorciada de programas de governo comprometidos com o enfrentamento das causas sociais que levam à necessidade de canalização dos vultosos recursos para projetos repressivos voltados a ilícitos praticados por pessoas que ainda se encontram na fase de desenvolvimento da sua personalidade, como são os adolescentes.

os associam ao perigo e à insegurança, imagens representadas pelo envolvimento passional nas causas religiosas, étnicas e éticas; pela precodidade com que se autonomizam dos controles tradicionais, constituem e desfazem elos efetivos e sexuais com uma naturalidade antes desconhecida; envolvem-se com tudo aquilo que remete ao perigo: esportes violentos, gangues, uso e tráfico de drogas, crime violento e organizado. Não sem motivos, mudou e vem mudando substantivamente a presença desses jovens na literatura especializada em desvio, crime e divergência".

16. A Resolução $n^{0} 113 / 2006$ do CONANDA assim dispõe: "Art. $6^{\circ} 0$ eixo da defesa dos direitos humanos de crianças e adolescentes caracteriza-se pela garantia do acesso à justiça, ou seja, pelo recurso às instâncias públicas e mecanismos jurídicos de proteção legal dos direitos humanos, gerais e especiais, da infância e da adolescência, para assegurar a impositividade deles e sua exigibilidade, em concreto. Art. $7^{\circ}$ Neste eixo, situa-se a atuação dos seguintes órgãos públicos: [...] V - polícia civil judiciária, inclusive a polícia técnica; VI - polícia militar.

17. Bauman (2016, p. 21) sustenta que o monopólio da força "requer que o poder (isto é, a capacidade de realizar) nas mãos do Estado seja grande o bastante - superior - para lhe dar vantagem num eventual confronto com poderes hostis ou prejudiciais à ordem, que ele instaura e guarda. Também requer que as instituições geridas pelo Estado sejam dotadas de autoridade exclusiva para decidir em que propósitos e objetivos o poder superior é aplicado. Satisfazer ambas as condições assegura ao Estado a capacidade prática de estabelecer a fronteira que separa "poder" (distribuição de força politicamente endossada) e "violência" (uso da força sem endosso político). Eu acredito que o ambiente de vulnerabilidade de hoje disseminado pode ser atribuído ao fato de essas condições não serem observadas. 0 "monopólio da força” pelo Estado é hoje quase uma ilusão, e cada vez mais é visto como tal”.
Uma rápida pesquisa na página oficial mantida pela Polícia Militar do Estado de Sergipe permite a localização de diversas notícias que relatam a apreensão de adolescentes em flagrante da prática de atos infracionais, uma delas, com o título PM apreendeu adolescente infrator com um revólver (POLÍCIA..., 2016), é ilustrada com fotografia na qual o adolescente apreendido é registrado deitado de costas, com as mãos algemadas, sendo colocadas sobre as suas costas a arma que supostamente portava e emblema militar com a inscrição "CPTUR". Tal imagem exibe tatuagem no braço direito do adolescente permite a rápida identificação indireta por alguém que tome conhecimento do fato.

A outra notícia, cuja manchete é $P M$ apreende em flagrante adolescente após assalto na Atalaia (POLÍCIA..., 2017), também é ilustrada com retrato frontal do adolescente apreendido, dessa vez com a estigmatizante tarja preta que cobre unicamente a parte dos olhos, situação que também viabiliza a rápida identificação do adolescente, com base em atributos de sua fisionomia localizados fora da região ocular e noutras informações fornecidas pelo órgão que, como já explicitado, está encarregado da execução da política de defesa dos direitos humanos de crianças e adolescentes. Difícil contestar, portanto, a conclusão de que vivemos em um estado de exceção permanente, apresentada por Luis Flávio Gomes (2016) e por diversos outros autores, já que o próprio órgão público não vê necessidade de cumprir deveres previstos expressamente no Estatuto da Criança e do Adolescente.

Essa espécie de cultura da vingança, que leva a Sociedade a ansiar por notícias de atuação das forças policiais com o máximo de rigor, é explicada por Giorgio Agamben (2010, p. 33) como fruto da cultura jurídica arcaica, marcada pela Lei do Talião, na qual a ordem jurídica não se baseia na ideia de sancionar "um fato transgressivo, mas constitui-se, sobretudo, através do repetir-se do mesmo ato sem sanção alguma, ou seja, como caso de exceção". Explica que a resposta jurídica "não é uma punição do primeiro, mas apresenta a sua inclusão na ordem jurídica, a violência como fato jurídico primordial (permittit enim lex parem 
vindicatam: Festo, 496, 15)" e conclui que “a exceção é a forma originária do direito” (AGAMBEN, 2010, p. 33).

A sociedade que rapidamente julga - com base em curto texto escrito com notória deficiência da técnica jornalística - o adolescente apreendido por guarnição da Polícia Militar logo após tentar furtar gêneros alimentícios move-se com base em "sublime 'sentimento moral', uma condição que, a partir da Primeira Guerra Mundial, se tornaria familiar nas sociedades de massa e nos grandes estados totalitários do nosso tempo" (AGAMBEN, 2010, p. 58). Esse perigoso movimento de crescente empoderamento das forças policiais preocupa pela potencialidade de fragilização das bases democráticas do Estado de Direito. Leva parcela significativa da população, inclusive pessoas com nível de instrução alto, a comemorar linchamentos de adolescentes, a partir de emoções que são fruto do próprio terrorismo midiático implantado no meio social, em movimento que se retro-alimenta.

Maria Stela Grossi Porto (2009 p. 229) analisa a problemática da transformação da própria segurança pública em mídia e expõe que o fenômeno vem ocorrendo em setores da polícia, exemplificando com a situação do Distrito Federal, onde policiais, com objetivo de:

Atestar maior credibilidade à sua atuação [...] estão produzindo jornais que, na contramão da cobertura da grande imprensa (que evita mostrar imagens chocantes em situações de violência), estampam em suas manchetes imagens de grande crueldade e realismo.

Segundo ela, tal noticiário exibe “corpos mutilados, deformados, decompostos" (PORTO, 2009 p. 229). Trata-se, portanto, de reafirmar as representações tão "recorrentes no espaço da segurança pública, segundo as quais "bandido bom é bandido morto"” (PORTO, 2009, p. 230).

Como será exposto a seguir, o comportamento adotado pelos sete veículos de comunicação pesquisados espelha essa tendência de incremento do grau de sensacionalismo no noticiário policial, que parte dos próprios órgãos públicos envolvidos no enfrentamento da criminalidade, como se isso fosse causar medo ${ }^{18}$ aos criminosos, quando o efeito é justamente o contrário, em razão do temor e do sentimento de insegurança, muitas vezes exagerado, que passa a afligir a população.

\section{ANÁLISE DAS NOTÍCIAS PESQUISADAS}

Fixadas as premissas dogmáticas relativas à tutela do direito fundamental ao respeito de crianças e adolescentes acusados da prática de ato infracional, notadamente quanto aos deveres de abstenção direcionados ao resguardo da honra e da privacidade, foram realizadas pesquisas de notícias publicadas no principal veículo de comunicação "online" de cada um dos sete municípios mais populosos do Estado de Sergipe, de acordo com o Censo Demográfico 2010, excluídos a Capital e os municípios integrantes da Região Metropolitana.

Foram colhidas amostras referentes aos municípios de Nossa Senhora da Glória, Simão Dias, Itabaianinha, Tobias Barreto, Estância, Itabaiana e Lagarto no mês de abril de 2017 por meio da ferramenta de busca do Google, identificando o veículo de maior relevância na pesquisa da expressão "menor apreendido [município]" e, dentro do domínio respectivo, a partir da combinação das expressões "menor”, “adolescente”, "apreendido”, “preso” e “apreensão”, foram impressas as dez notícias mais relevantes de acordo com a mesma ferramenta.

A utilização da expressão "menor”, mesmo diante da carga semântica inerente à Doutrina da Situação Irregular que ela ostenta, decorreu da constatação, em prospecções preliminares, que a linguagem utilizada pela maioria dos veículos de comunicação dos municípios médios ainda está conectada à cultura menorista, a exemplo do que ocorre no Sistema de Justiça, como apontam estudos de Sposato (2013), Saraiva (2016), Digiácomo (2013) e Ishida (2016).

18. Luigi Ferrajoli (2006, p. 192), dissertando sobre a estratégia de política criminal baseada na prevenção geral, centrada na ameaça da pena, pondera que ela não impede "o terrorismo penal legislativo", por ser, "mais eficaz quanto mais elevadas e severas forem as penas cominadas". Adverte que, por essa lógica, o trágico ponto de chegada sera "a pena de morte para todos os crimes". 
A opção por pesquisar em veículos de comunicação "online" foi adotada levando em conta dois fatores. Primeiro, o baixo custo para coleta de dados, na medida em que foi necessário unicamente um computador conectado à internet. 0 segundo fator diz respeito à hegemonia desse meio de informação, antes ocupado por periódicos impressos. Tratando-se de cidades médias, com população oscilando entre 32.497 (trinta e dois mil, quatrocentos e noventa e sete) habitantes, no caso de Nossa Senhora da Glória e 94.861 (noventa e quatro mil, oitocentos e sessenta e um) habitantes, no Município de Lagarto, não há infraestrutura de comunicação por meio televisivo, alimentando-se a população de notícias produzidas pela sede da emissora em Aracaju.

A pesquisa em notícias veiculadas por rádios, embora necessária e relevante, considerando a quantidade de noticiários que violam os deveres jurídicos de proteção aos adolescentes, consumiria muito mais tempo para a coleta das amostras e não poderia apresentar execução retrospectiva, como no presente estudo, demandando a gravação de longas horas de programação para posterior análise minuciosa a fim de encontrar referências nas falas dos apresentadores e repórteres que levassem à identificação dos adolescentes, seja pela sua descrição física, seja pela indicação de dados pessoais que, somados a informações que circulam entre as pessoas, permitem esse identificação.

As notícias localizadas nos sete veículos de comunicação, a partir dos parâmetros de busca antes mencionados, foram analisadas com base nos seguintes parâmetros - (a) divulga, "total ou parcialmente, sem autorização devida [...], nome, ato ou documento de procedimento policial, administrativo ou judicial relativo a criança ou adolescente a que se atribua ato infracional (art. 247, caput, do ECA)"; (b) "exibe, total ou parcialmente, fotografia de criança ou adolescente envolvido em ato infracional, ou qualquer ilustração que the diga respeito" (art. $247, \S 1^{\circ}$, primeira parte, do ECA); e (c) faz referência a "nome, apelido, filiação, parentesco, residência e, inclusive, iniciais do nome e sobrenome" (art. 247, $\S 1^{\circ}$, parte final, c/c art. 143, parágrafo único, do ECA).
As 70 (setenta) notícias foram localizadas em veículos de comunicação que utilizam os seguintes domínios:

- Nossa Senhora da Glória: pingounoticias.com.br

- Simão Dias: simaodiascomoeuvejo.com.br

- Itabaianinha: gataamarrada.com.br

- Tobias Barreto: portaltobiense.com.br

- Estância: infonet.com.br

- Itabaiana: gilsondeoliveira.com.br

- Lagarto: lagartocomoeuvejo.com.br

Todas as notícias incorreram na vedação de divulgação de procedimento policial que dizem respeito a adolescente acusado da prática de ato infracional, revelando que a abordagem midiática do fenômeno infracional passa pelo enfoque da atuação policial contra pessoas supostamente investida de altos poderes de causar danos à Sociedade. Em outras palavras, as mídias "online" dos municípios do interior sergipano, conforme demonstra a integralidade da amostra coletada, parte de um discurso equivocado, colocando adolescentes na qualidade de algozes da sociedade e as forças policiais como representantes do "bem", daquela parte do Estado que não se omite no enfretamento da violência praticada pelos adolescentes.

Falta a tais notícias o necessário juízo crítico do bom jornalismo ${ }^{19}$, responsável por levantar questio-

19. Consta do "Guia de referência para a cobertura jornalística", elaborado pela organização não governamental ANDI - Comunicação e Direitos, em parceria com a Secretaria de Direitos Humanos da Presidência da República, que "o jornalista deve apurar detalhes relevantes sobre os personagens da notícia, como grau de escolaridade, condições de moradia, situação familiar e tipo de envolvimento entre vítima e agressor. Quando a história é bem contada, o leitor entende os contextos sociais de exclusão que vulnerabilizam os adolescentes e favorecem a prática de atos infracionais. [...] Não é possível fazer uma boa matéria ouvindo apenas a Polícia, por exemplo. Além da vítima ou de seus familiares, é necessário dar voz ao acusado (lembrando que, no momento da apreensão, sua condição ainda é de suspeito), sem expor sua identidade, obviamente. [...] Importante lembrar, ainda, que o Estatuto da Criança e do Adolescente prevê sanções para os veículos de comunicação que praticarem esse tipo de abuso. [...] Não publique textos nem divulgue fotos ou vídeos que, mesmo desfocados ou com nomes omitidos, possam provocar risco para os jovens e seus familiares. [...] 0 uso de tarjas pretas sobre os olhos não é uma solução eficiente, pois a identificação pode ocorrer a partir de aspectos de outras partes do corpo ou do vestuário. Além disso, o recurso tem sido condenado por alguns especialistas, com base no pressuposto de que pode remeter a significados anteriores à Doutrina da Proteção Integral, quando esse tipo de tratamento editorial de fotos de crianças e adolescentes em situação de vulnerabilidade social era recorrente" (BRASIL, 2012, p. 71-72). 
namentos de fundo social, analisando a problemática daquele específico ato de violência em conjunto com outras violências exercidas historicamente, que têm como vítima o adolescente acusado e uma longa cadeia de ascendentes que não tiveram mínimos direitos sociais respeitados pelo Estado que lança agora sobre uma pessoa em desenvolvimento toda a força punitiva de seu aparelho repressor policial. Para tais jovens, muito mais relevante seria a atuação dos órgãos que integram o Sistema de Garantia dos Direitos das Crianças e dos Adolescentes, por meio de serviços nas áreas social, educacional e de saúde.

Ao lado dessa ilicitude, também foram apuradas violações baseadas nos dois outros parâmetros definidos na metodologia desse trabalho, com 40 (quarenta) notícias, ou seja, $57 \%$ (cinquenta por cento) da amostra, exibindo total ou parcialmente fotografias dos adolescentes acusados e 35 (trinta) e cinco, ou seja, 50\% (cinquenta por cento) da amostra, apresen- tando informações que viabilizam a identificação do adolescente por outros meios que não o registro de sua imagem.

Os gráficos a seguir detalham a incidência de cada uma das modalidades de ilícito utilizadas para análise do material coletado, cabendo rememorar que os parâmetros são os seguintes: (a) divulga, "total ou parcialmente, sem autorização devida [...], nome, ato ou documento de procedimento policial, administrativo ou judicial relativo a criança ou adolescente a que se atribua ato infracional (art. 247, caput, do ECA)"; (b) "exibe, total ou parcialmente, fotografia de criança ou adolescente envolvido em ato infracional, ou qualquer ilustração que lhe diga respeito" (art. 247, § $1^{\circ}$, primeira parte, do ECA); e (c) faz referência a "nome, apelido, filiação, parentesco, residência e, inclusive, iniciais do nome e sobrenome" (art. 247, § $1^{\circ}$, parte final, c/c art. 143, parágrafo único, do ECA).

Gráfico 1: incidência das três modalidades de ilícito em toda a amostra.

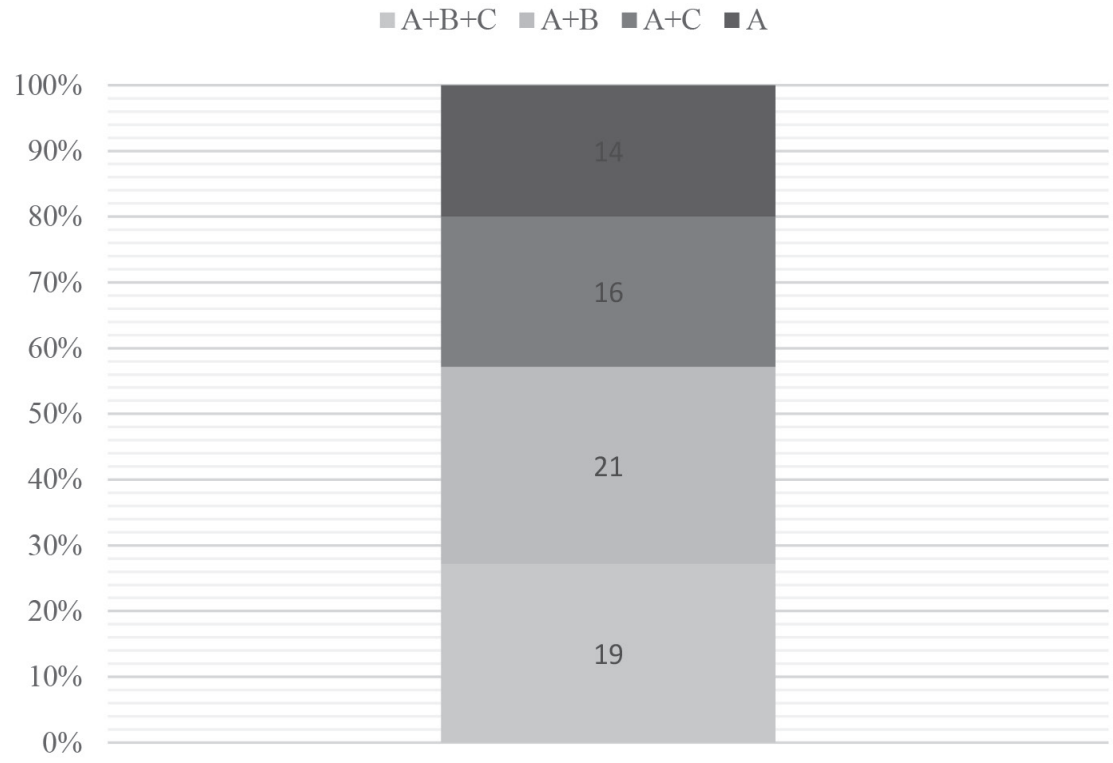

Fonte: elaborado pelo autor 
Gráfico 2: incidência das modalidades de ilícito em cada um dos veículos pesquisados.

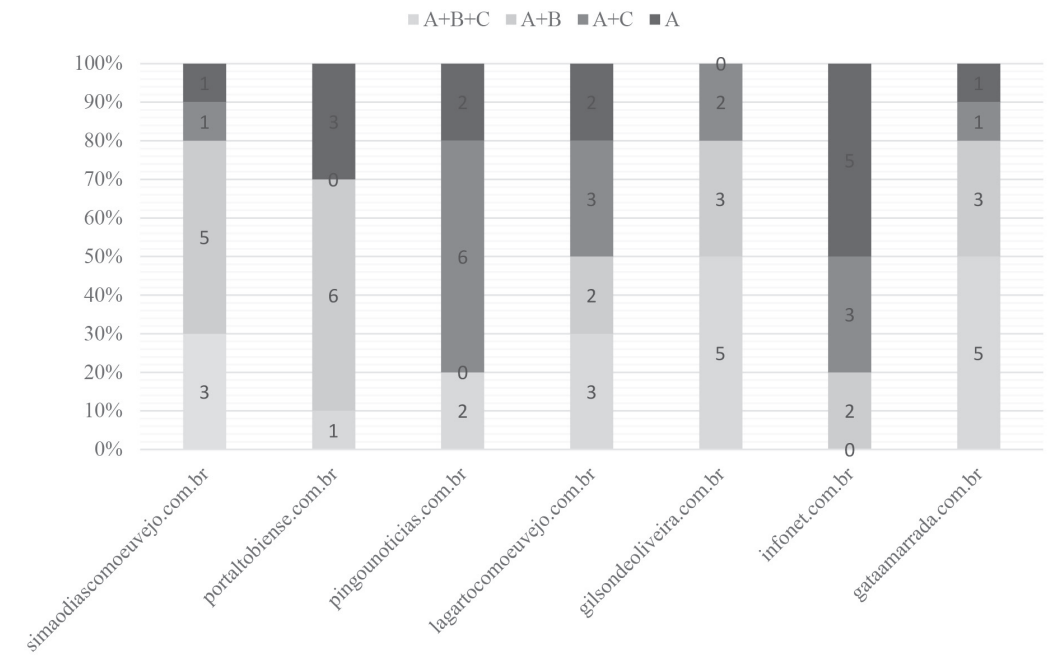

Fonte: elaborado pelo autor

Aspecto relevante para a interpretação dos dados coletados é a dispersão das setenta notícias que foram coletadas em abril de 2017. Como se observa no gráfico abaixo, apenas 21 (vinte e uma) delas foram

Gráfico 3: dispersão das notícias de acordo com a data de publicação.

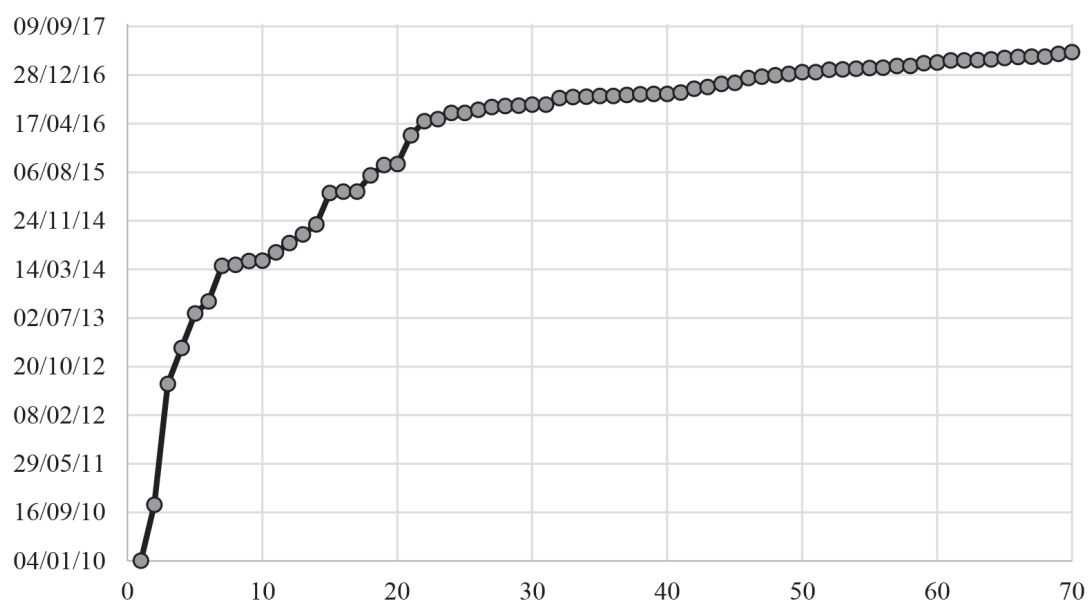

publicadas antes de 17/4/2016. As outras 49 (quarenta e nove) notícias, ou seja, $70 \%$ (setenta por cento) da amostra foram publicadas com menos de um ano da coleta. 
Cumpre frisar que a metodologia de pesquisa consistia na identificação das dez primeiras ocorrências para cada um dos veículos de comunicação, segundo o mecanismo do Google muitas outras notícias poderiam ter sido localizadas e analisadas. No entanto, verificar a concentração de apenas $30 \%$ (trinta por cento) da amostra com distância temporal superior a um ano atesta a facilidade com a qual tais notícias podem ser localizadas.

\section{ESTRATÉGIAS DE ENFRENTAMENTO}

Diante do grande número de notícias e da facilidade com a qual elas foram localizadas, todas violando ao menos um dos deveres impostos pelas normas jurídicas que vigoram no Brasil aos veículos de comunicação, com a finalidade de tutela ao direito fundamental ao respeito de adolescentes acusados da prática de atos infracionais, é possível concluir pela baixíssima efetividade da política pública de fiscalização e de repressão a tais ilícitos, com grande contribuição do sistema de justiça para isso, por ser ele encarregado legalmente da punição daqueles que praticam infrações às normas administrativas do Estatuto da Criança e do Adolescente.

Para modificação desse lamentável quadro de violação e de inação estatal, são propostas cinco estratégias de enfrentamento por parte dos órgãos que integram o Sistema de Garantia dos Direitos das Crianças e dos Adolescentes e pelas instâncias da sociedade civil que militam na área de defesa dos direitos humanos.

A primeira é melhorar o monitoramento e a comunicação entre os órgãos, de maneira que todas as notícias de prática desse tipo de infração administrativa cheguem rapidamente ao conhecimento do Poder Judiciário, o que pode ocorrer pelo envio de mensagens eletrônicas, realização de reuniões periódicas, estreitamente dos vínculos institucionais por meio da formação de comitês, dentre outras maneiras de integrar os órgãos do referido Sistema.
Cabe enfatizar que, a exemplo desta pesquisa, os custos para acompanhamento das publicações veiculadas pela Internet são consideravelmente baixos e com perspectivas de retorno tanto por meio da aplicação das sanções pelo Poder Judiciário, levando a reforço no financiamento do Sistema, quanto pela identificação de outras formas de violação de direitos humanos relatadas nas notícias e nos comentários publicados pelos leitores. Nesse sentido, as organizações não governamentais, por menor que seja a sua estrutura administrativa, podem contribuir com dito monitoramento.

Como segunda estratégia, propõe a priorização dos procedimentos judicias e extrajudiciais direcionados à repressão de tais ilícitos. Embora tais infrações administrativas sejam processadas por meio de rito extremamente simplificado, não é incomum a tramitação lenta dos feitos, levando muitas vezes à prescrição. Por se tratar de causa ligada a direitos de crianças e adolescentes, ao menos no plano difuso, cabe aos magistrados que atuam em varas únicas, conceder a prioridade prevista em lei para as demais demandas fundamentadas no Estatuto da Criança e do Adolescente.

A terceira estratégia, que também objetiva a celeridade no trâmite dos feitos, é a de criação de varas especializadas e a instituição de núcleos regionais para atuação coordenada das promotorias de justiça com atribuições de defesa dos direitos de crianças e adolescentes. A partir dessa atuação especializada, procedimentos podem ser racionalizados e problemas regionais enfrentados com mais celeridade e eficiência. Notícias publicadas por um veículo de comunicação de uma cidade média são reproduzidas em outros veículos da região, exigindo repressão uniforme para eliminação da notícia ou redução de sua repercussão na maior medida possível.

0 reforço da tutela do direito ao respeito pela via coletiva é a quarta estratégia direcionada a dotar o enfrentamento desse tipo de ilícito de mais efetividade, pois ela viabiliza a ampliação das sanções aos veículos de comunicação que reiteram a prática de publicar notícias, mesmo demandados em razão das infrações 
administrativas. Caracterizada a intenção de violar o direito ao respeito dos adolescentes, de forma reiterada e com o intuito de lucro, já que tal postura leva ao aumento da audiência, tanto o Ministério Público quanto instâncias da sociedade civil legitimadas para o ajuizamento de ação civil pública podem pleitear a fixação de multas mais elevadas do que as previstas no Estatuto da Criança e do Adolescente, inclusive para remoção em bloco das notícias que ainda estejam no ar, mesmo após o processamento das representações apresentadas pela Promotoria de Justiça.

Nessas ações cíveis, como quinta estratégia, pode ser requerida a condenação, por meio de tutela ressarcitória, para ser compensada a lesão a direitos transindividuais, considerando a ocorrência de dano moral coletivo.

Cumpre destacar o importante papel que a sociedade civil pode e deve desempenhar, ajuizando ações civis públicas para a tutela dos direitos de crianças e adolescentes, fazendo uso da legitimidade conferida pelo sistema de tutela coletiva brasileiro, ou representando ao Ministério Público, caso não haja estrutura de assessoria jurídica apta ao acompanhamento desse tipo de demanda, a partir do simples monitoramento das notícias publicadas na internet e da remessa, também por meio eletrônico, das informações à Promotoria de Justiça com atribuições, à Procuradoria-Geral de Justiça ou mesmo à ouvidoria.

\section{REFERÊNCIAS}

ADORNO, Sérgio. A Delinquência juvenil em São Paulo: mitos, imagens e fatos. Pro-Posições, v.13, n.3 (39), p.45-70, set-dez. 2002.

AGAMBEN, Giorgio. Homo Sacer: o poder do soberano e a vida nua I. Tradução Henrique Burigo. 2.ed. Belo Horizonte: UFMG, 2010.

AMIN, Andréa Rodrigues. Evolução história do direito da criança e do adolescente. In: MACIEL, Kátia Regina
Ferreira Lobo Andrade. Curso de direito da criança

e do adolescente: aspectos teóricos e práticos. Organizadora. 6.ed. São Paulo: Saraiva, 2013.

BAUMAN, Zygmunt; MAURO, Ezio. Babel: entre a incerteza e a esperança. Rio de Janeiro: Zahar, 2016.

BRASIL. Secretaria de Direitos Humanos da Presidência da República. ANDI - Comunicação e Direitos Humanos. Adolescentes em conflito com a lei: guia de referência para a cobertura jornalística. Brasília, 2012. Disponível em <http://www.andi.org. $\mathrm{br} /$ publicacao/adolescentes-em-conflito-com-leiguia-de-referencia-para-cobertura-jornalistica>. Acesso em: 26 jun. 2017.

\section{CUNHA JÚNIOR, Dirley da. Curso de direito}

constitucional. 3.ed. Salvador: JusPodivm, 2009.

DIGIÁCOMO, Murillo José; DIGIÁCOMO, Ildeara de Amorim. Estatuto da criança e do adolescente anotado e interpretado. 6.ed. Curitiba: MPPR, 2013.

FERRAJOLI, Luigi. Direito e razão: teoria do garantismo penal. São Paulo: RT, 2006.

FRASSETO, Flávio Frasseto. Apuração de ato infracional e execução de medida sócio-educativa: considerações sobre a defesa técnica de adolescentes. São Paulo: Associação Nacional dos Centros de Defesa da Criança e do Adolescente, 2005.

GOMES, Luiz Flávio; GAZOTO, Luís Wanderley. Populismo penal legislativo: a tragédia que não assusta as sociedades de massas. Salvador: JusPodivm, 2016.

GRAU, Eros Roberto. A ordem econômica na constituição de 1988: interpretação e crítica. 11.ed. São Paulo: Malheiros, 2006.

ISHIDA, Válter K. Estatuto da criança e do

adolescente. 17.ed. Salvador: JusPodivm, 2016. 
MARINONI, Luiz Guilherme. Técnica processual e tutela dos direitos. São Paulo: Revista dos Tribunais, 2010.

NUNES JÚNIOR, Vidal Serrano. Direito e jornalismo. São Paulo: Verbatim, 2011.

POLÍCIA Militar do Estado de Sergipe. PM apreendeu adolescente infrator com um revólver. 20 out.

2016. Disponível em <http://www.pm.se.gov.br/pmapreendeu-adolescente-infrator-com-um-revolver/>. Acesso em: 23 jun. 2017.

POLÍCIA Militar do Estado de Sergipe. PM apreende em flagrante adolescente após assalto na Atalaia. 24 abr. 2017. Disponível em <http://www.pm.se.gov. $\mathrm{br} / \mathrm{pm}$-apreende-em-flagrante-adolescente-aposassalto-na-atalaia/>. Acesso em: 23 jun. 2017.

PORTO, Maria Stela Grossi. Mídia, Segurança Pública e Representações Sociais. Tempo Social. Revista de Sociologia da USP, v.21, n.2, p.211-233, nov. 2009.

SARAIVA, João Batista Costa. Adolescente e responsabilidade penal: da indiferença à proteção integral. 5.ed. Porto Alegre: Livraria do Advogado, 2016. SPOSATO, Karyna Batista. Direito penal de adolescentes: elementos para uma teoria garantista. São Paulo: Saraiva, 2013. 
Data da submissão: 3 de Julho de 2017

Avaliado em: 10 de Agosto de 2017 (Avaliador A) Avaliado em: 29 de Agosto de 2017 (Avaliador B) Aceito em: 20 de Agosto de 2017
1. Aluno regular do Mestrando em Direitos Humanos da UNIT. Professor do Curso de Direito da FASETE. Membro do Grupo de Pesquisa "Direito Constitucional: sociedade, política e economia", do Fórum Nacional dos Membros do Ministério Público da Infância e Adolescência - Proinfância e do Instituto Brasileiro de Direito da Criança e do Adolescente - IBDCRIA/ABMP. 